\title{
Ultrasonik Destekli Ekstraksiyon (UAE) Yöntemi ile Hazırlanan Kuşburnu Meyvesi Kabuk ve Çekirdek Kısımlarının Antioksidan Aktivitesinin Belirlenmesi
}

\author{
Arzu ÖZGEN*, Nurcihan TAN ERKOÇ** Ömer Faruk TAŞTAN****, \\ Funda PEHLEVAN****
}

\section{$\ddot{O}_{z}$}

Amaç: Bu çalışmada Gümüşhane ilinde doğal olarak yetişen kuşburnu meyvelerinin hem kabuk hem de çekirdeğinin (tohum) ultrasonik destekli ekstraksiyon (UAE) yöntemi kullanılarak hazırlanan etanol ekstraktlarının 2,2-diphenyl-1-picryl-hydrazil (DPPH) metodu ile antioksidan aktivitelerinin kıyaslanması amaçlanmıştır.

Yöntem: Çalışmada kuşburnu meyvesinin kabuk ve çekirdeğine ait kısımlarından farklı zaman aralıklarında UAE yöntemi kullanılarak hazırlanmış olan ekstraktların antioksidan aktivitesi 2,2diphenyl-1-picryl-hydrazil (DPPH) metodu ile belirlenmiştir.

Bulgular: 2 dakika süreyle UAE destekli ekstraksiyona ait kuşburnu ekstraktlarının serbest radikal yakalama aktivitesinin hem kabuk hem de çekirdek için $\mathrm{IC}_{50}$ değeri sırasıyla $0.69 \pm 0.005$ $\mathrm{mg} \mathrm{mL} \mathrm{m}^{-1}$ ve $0.39 \pm 0.0007 \mathrm{mg} \mathrm{mL}^{-1}$ olarak hesaplanmıştır. Kuşburnu meyvesine ait çekirdek kısmının kabuk kısmına göre daha yüksek bir radikal süpürücü aktiviteye sahip olduğu bulunmuştur.

\section{Özgün Araştırma Makalesi (Original Research Article)}

Geliş / Received: 24.03.2021 \& Kabul / Accepted: 05.08.2021

DOI: https://doi.org/10.38079/iqusabder.902242

* Dr. Öğr. Üyesi, İstanbul Gelişim Üniversitesi, Sağlık Hizmetleri Meslek Yüksekokulu, Tıbbi Laboratuvar Teknikleri Programı, İstanbul, Türkiye, E-posta: aozgen@gelisim.edu.tr ORCID https://orcid.org/0000-0003-2104-6019

** Öğr. Gör., İstanbul Gelişim Üniversitesi, Sağlık Hizmetleri Meslek Yüksekokulu, Tıbbi Laboratuvar Teknikleri Programı, İstanbul, Türkiye, E-posta: ntan@gelisim.edu.tr ORCID https://orcid.org/0000-0002-0029-0197

${ }^{* * *}$ Kurucu Ortak, Nordik Kozmetik ve Bitkisel Ürünler San. Tic. Ltd. Şti., İstanbul, Türkiye, E-posta: oftastan@gmail.com ORCID https://orcid.org/o000-0003-1174-5860

**** Öğr. Gör., İstanbul Gelişim Üniversitesi, Sağlık Hizmetleri Meslek Yüksekokulu, Tıbbi Laboratuvar Teknikleri Programı, İstanbul, Türkiye, E-posta: fpehlevan@gelisim.edu.tr ORCID https://orcid.org/0000-0003-3906-977X 
Sonuç: Elde edilen verilerin literatürde mevcut bulunan verilere göre daha etkili olduğu sonucuna varılmış olup bunun kullanılan ekstraksiyon yöntemi ile ilişkili olduğu düşünülmektedir.

Anahtar Sözcükler: Antioksidan aktivite, kuşburnu, ultrasonik destekli ekstraksiyon, Rosa canina.

\title{
Determination of Antioxidant Activity of Rosehip Fruit Peel and Seed Parts Prepared by Ultrasonic Assisted Extraction (UAE) Method
}

\begin{abstract}
Aim: In this study, it was aimed to compare the antioxidant activities of ethanol extracts prepared using ultrasonically assisted extraction (UAE) method of both peel and seed of rosehip fruits growing naturally in Gümüşhane province with the 2,2-diphenyl-1-picryl-hydrazyl (DPPH) method.

Method: In this study, the antioxidant activity of the extracts of the peel and seed parts of the rosehip fruit prepared using UAE method at different time intervals was determined by 2,2diphenyl-1-picryl-hydrazyl (DPPH) method.

Results: The free radical scavenging activity of $\mathrm{IC}_{50}$ value rosehip extracts of UAE assisted extraction for 2 minutes was calculated as $0.69 \pm 0.005 \mathrm{mg} \mathrm{mL}^{-1}$ for the peel part and $0.39 \pm$ $0.0007 \mathrm{mg} \mathrm{mL}^{-1}$ for the seed part. The seed part of the rosehip fruit has been found to have a higher radical scavenging activity than the peel part.
\end{abstract}

Conclusion: It has been concluded that the data obtained are more effective than the data available in the literature, and this is thought to be related to the extraction method used.

Keywords: Antioxidant activity, rosehip, ultrasound assisted extraction, Rosa canina.

\section{Giriș}

Canlı organizmalar metabolik olaylar ve inflamasyon gibi fizyolojik süreçlerde reaktif oksijen türlerini (ROT) endojen olarak üretmektedirler ${ }^{1,2}$. Hücrelerin çoğalması ve farklılaşması gibi önemli biyolojik süreçleri içeren temel olayların devamlılığı için az seviyede de olsa ROT'ne ihtiyaç bulunmaktadır¹,3. Diğer bir ifadeyle canlılık olaylarının devamı için oksidan-antioksidan dengesinin korunması organizma için önem arz etmektedir. Süperoksit anyonu, hidrojen peroksit, hidroksil radikali ve lipit peroksitler gibi ROT formları aerobik metabolizmanın normal ürünleri olarak oluşturulmaktadır ancak yüksek oranda üretildiklerinde ya da eliminasyonlarının azalması durumunda 
oksidatif stres meydana gelmektedir. Bu sürecin takibinde ROT'lar membran lipidleri, nükleik asitler, karbonhidratlar ve proteinler gibi makromoleküllere etki eder ve hasara yol açarlar ${ }^{4-6}$.

Bitki hücreleri de diğer hücreler gibi biyotik ve abiyotik stres koşulları altında reaktif oksijen türlerini üretmekte olup bu üretim neticesinde oksidatif stres meydana

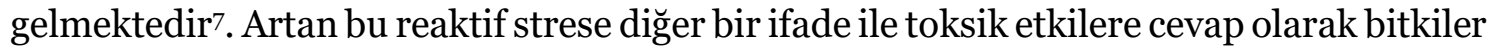
süperoksit dismutaz (SOD), katalaz (CAT), glutatyon peroksidaz (GPx) ve glutatyon redüktaz (GR) gibi enzimatik olan ve glutatyon, prolin, karotenoidler, fenolik asitler, flavonoidler, vitamin $\mathrm{C}$, vitamin $\mathrm{E}$, terpen ve tanninler gibi enzimatik olmayan sekonder metabolitler olan antioksidanları üretirler ${ }^{8}$. Üretilen bu moleküller serbest radikal temizleyicileri, indirgeyici ajanlar ve metal şelatlar olarak işlev görürler ${ }^{-11}$.

Rosaceae familyasına ait olan Rosa cinsi ılıman ve subtropikal bölgeler olmak üzere çoğunlukla Kuzey yarımkürede doğal olarak yetişmekte olup yaklaşık olarak 200 türe sahiptir ${ }^{12,13}$. Halk arasında kuşburnu olarak da bilinen Rosa canina L. reçel, çay ve içecek gibi çeşitli gıda preparatlarında kullanılmaktadır. C vitamini, tokoferoller, fenolik bileşikler, karotenoidler, şekerler, organik asitler ve esansiyel yă̆ asitleri gibi değerli besin öğelerine sahip olan kuşburnunun antioksidan, antikanserojen, antienflamatuar ve anti-obezite aktiviteleri gibi çeşitli biyoaktivitelerinin olduğunu gösteren çalışmalar mevcuttur ${ }^{14-18}$.

Bu çalışmada Gümüşhane ilinde doğal olarak yetişen kuşburnu meyvelerinin hem kabuk hem de çekirdeğinin (tohum) UAE yöntemi kullanılarak hazırlanan etanol ekstraktlarının DPPH metodu ile antioksidan aktivitelerinin kıyaslanması amaçlanmıştır.

\section{Gereç ve Yöntem}

2018 yılında toplanan kuşburnu örnekleri direk güneş ışığı almayan gölge ve hafif hava akımının olduğu bir alanda kurutulmuştur. Kurutmanın ardından mekanik olarak toz haline getirilmiş kuşburnu meyve kabuk kısmı ve çekirdeğine ait kısımlar 200 mg olacak şekilde tartılarak $5 \mathrm{~mL}$ etanol (\%99,5 saflıkta) içerisinde ultrasonik banyoda (Bandelin sonorex, RK $100 \mathrm{H}) 35 \mathrm{kHz}, 37^{\circ} \mathrm{C}$ de ve en kısa süre içinde en verimli sonuçların alındığı zaman aralıkları olan sürelerde $(2,4,6,8,10$ dakika) ultrasonik destekli ekstraksiyon işlemine tabi tutuldu. Örnekler 6oooxg'de 15 dakika santrifüj edildi. Üst faz alınıp 
Whatmann kağıdı kullanılarak filtre edildi. Etanolün tamamen uzaklaştırılması için 37 ${ }^{\circ} \mathrm{C}$ 'de etüvde bekletildi. Elde edilen kabuk ve çekirdek eksraktları antioksidan aktivite işlemleri yapılana kadar $+4{ }^{\circ} \mathrm{C}$ 'de muhafaza edildi.

\section{DPPH (1,1-difenil-2-pikril-hidrazil) Radikal Yakalama Aktivitesi Tayini}

Kuşburnu kabuk ve çekirdeğine ait kısımlarından hazırlanan ekstraktların antioksidan aktivitesi DPPH yakalama aktivitesi metodu kullanılarak Brand-Williams, 1995’ e göre yapildi ${ }^{19}$.

Saf etanolde çözülmek üzere $20 \mathrm{mg} \mathrm{L}^{-1}$ konsantrasyonda DPPH (Sigma D9132) çözeltisi hazırlandı. Daha sonraki aşamada bitki ekstraktlarının (10 mg/10 mL etanol çözeltisinden) sırasıyla 100, 250, 500, 750 ve $1000 \mu \mathrm{g} \mathrm{mL} \mathrm{m}^{-1}$ olacak şekilde seri dilüsyonları hazırlandı. $1.5 \mathrm{~mL}$ DPPH solüsyonu üzerine her bir bitki ekstrakt dilüsyonlarından $0.75 \mathrm{~mL}$ eklendi ve 30 dakika karanlık bir ortamda ve oda sıcaklı̆̆ında inkübe edildi. Karışımın absorbans değeri 517 nm'de ölçüldü. Kör olarak etanol kullanıldı ve $100,250,500,750$ ve $1000 \mu \mathrm{g} \mathrm{mL}^{-1}$ konsantrasyonlarda hazırlanan Bütillenmiş hidroksi anisol (BHA), Bütillenmiş hidroksi toluen (BHT) ve Askorbik asit (AA) solüsyonları ise standart antioksidanlar olarak kullanıldı.

Antioksidan aktivite \% cinsinden aşağıda verilen formül kullanılarak hesaplandı.

DPPH Yakalama Aktivitesi $(\%)=\left[\left(\mathrm{A}_{0}-\mathrm{A}_{1}\right) / \mathrm{A}_{0} \times 100\right]$

( $\mathrm{A}_{0}$ : Kontrol Absorbansı, $\mathrm{A}_{1}$ : Ekstrakt Absorbansı)

\section{Bulgular}

$\mathrm{Bu}$ çalışmada kuşburnu kabuk ve çekirdeğine ait kısımlarından UAE yöntemi kullanılarak hazırlanmış olan ekstraktların antioksidan aktivitesi DPPH radikal yakalama kapasitesi yönünden incelenmiştir. Kuşburnu meyve kabuğu ve çekirdek kısmına ait öğütülmüş materyal 2, 4, 6, 8 ve 10 dakika boyunca etanol içerisinde UAE yöntemi kullanılarak ekstrakte edildi. 2 dakikalık ekstraksiyon süresinde kuşburnu ekstraktlarının 100, 250, 500, 750, $1000 \mu \mathrm{g} \mathrm{mL}^{-1}$ konsantrasyonlarındaki serbest radikal yakalama aktivitesinin hem meyve kabuğu hem de çekirdek kısmı için $\mathrm{IC}_{50}$ değeri sirasıyla 0,69 $\pm 0,005 \mathrm{mg} \mathrm{mL}^{-1}$ ve 0,39 $\pm 0,0007 \mathrm{mg} \mathrm{mL}^{-1}$ olarak hesaplandı. Kontrol grubu olarak kullanılan BHT, BHA ve AA solüsyonlarının 100, 250, 500, 750, $1000 \mu \mathrm{g} \mathrm{mL}^{-1}$ konsantrasyonlarındaki $\mathrm{IC}_{50}$ değerleri ise sırasıyla $0,041 \pm 0,002,0,34 \pm 0,002$ ve 0,23 
\pm 0,006 mg mL-1 olarak hesaplandı. $\mathrm{IC}_{50}$ değerinin düşük olması antioksidan aktivitenin yüksek olması anlamına gelmektedir. Dolayısıyla $\mathrm{IC}_{50}$ değeri $0,39 \pm 0,0007 \mathrm{mg} \mathrm{mL}^{-1}$ olan kuşburnunun çekirdek kısmının kabuk kısmına göre daha yüksek bir radikal süpürücü aktiviteye sahip olduğu görülmektedir.

Kuşburnu meyve kabuk kısmının $750 \mu \mathrm{g} \mathrm{mL} \mathrm{mL}^{-1}$ ve $1000 \mu \mathrm{g} \mathrm{mL} \mathrm{m}^{-1}$ konsantrasyonlarında ki DPPH \% yakalama aktiviteleri Şekil 1'de gösterilmiştir. 4 dakika süreli ekstraksiyon Şartlarında $750 \mu \mathrm{g} \mathrm{mL} \mathrm{mL}^{-1}$ ve $1000 \mu \mathrm{g} \mathrm{mL}^{-1}$ konsantrasyonlarda ki DPPH \% inhibisyon değeri sırasıyla \%72,92 ve \%80,18 olarak belirlenmiştir.

Şekil 1. Standart solüsyonların (BHA, BHT ve AA) ve kuşburnu kabuğu ekstraktlarının (750 $\mu \mathrm{g} \mathrm{mL} \mathrm{m}^{-1}$ ve $\left.1000 \mu \mathrm{g} \mathrm{mL} \mathrm{m}^{-1}\right) \% \mathrm{DPPH}$ radikal yakalama aktivitesi

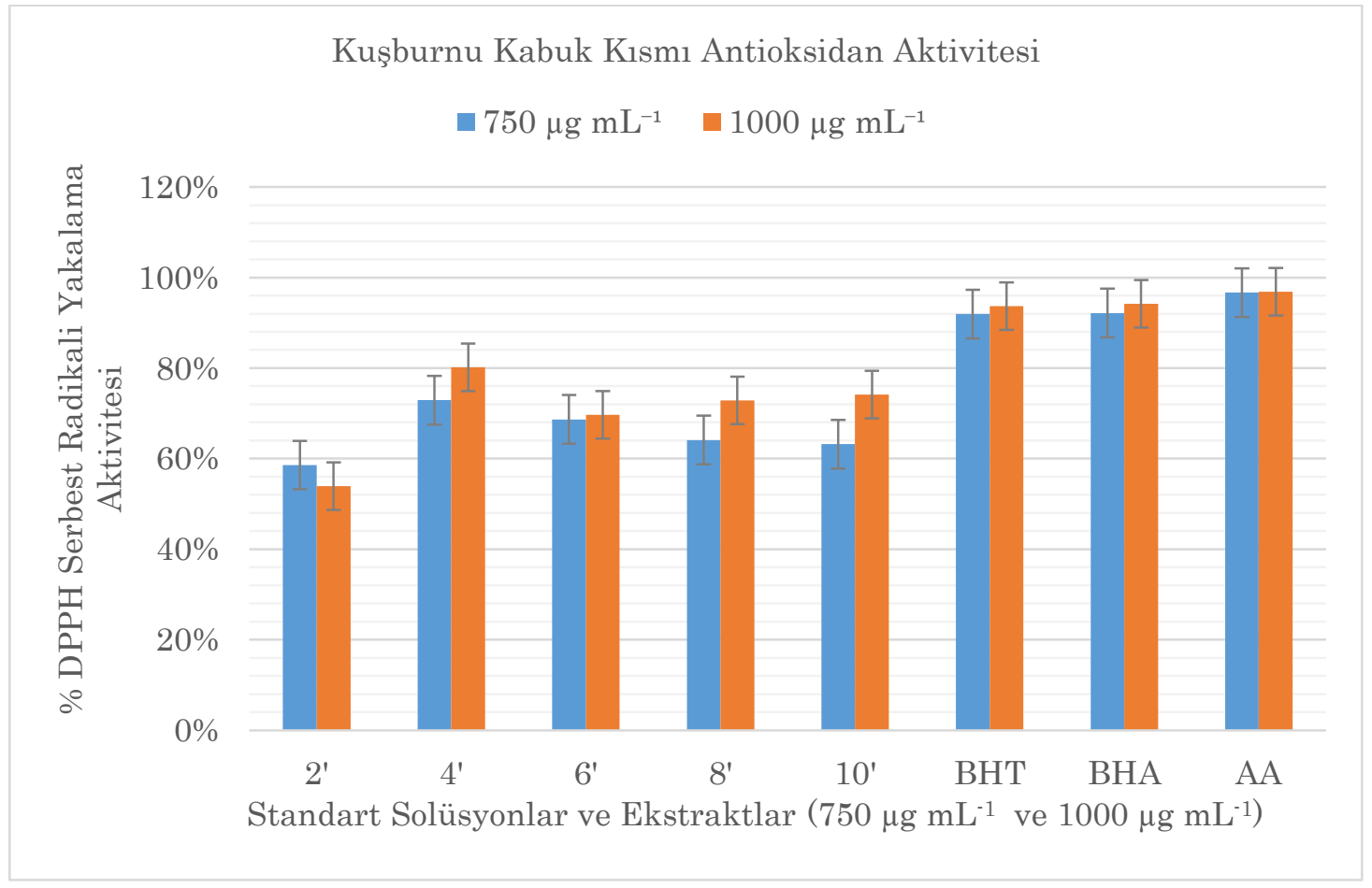

Kuşburnu çekirdeğinin $250 \mu \mathrm{g} \mathrm{mL}^{-1}$ ve $500 \mu \mathrm{g} \mathrm{mL} \mathrm{m}^{-1}$ konsantrasyonlarındaki DPPH \% inhibisyon değerleri Şekil 2'de gösterilmiştir. 6 dakika süreli ekstraktta $250 \mu \mathrm{g} \mathrm{mL}^{-1}$ ve

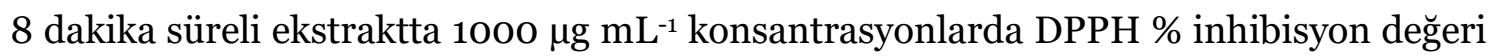
sırasıyla \%58,78 ve \%53,73 olarak belirlenmiştir. 
Şekil 2. Standart solüsyonların ve kuşburnu çekirdeği ekstraktının $\left(250 \mu \mathrm{g} \mathrm{mL}^{-1}\right.$ ve 500 $\left.\mu \mathrm{g} \mathrm{mL}^{-1}\right)$ \%DPPH serbest radikal yakalama aktivitesi

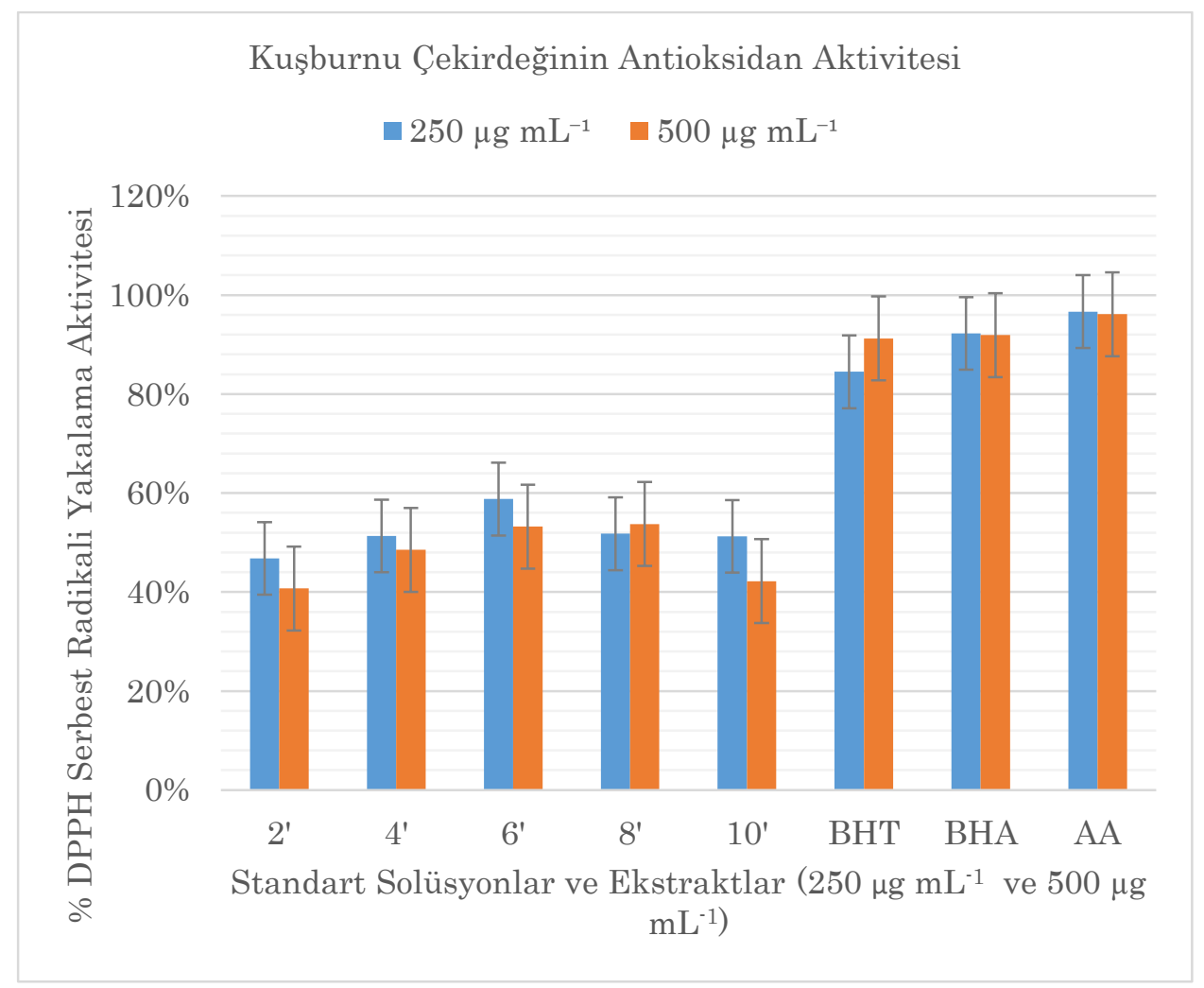

\section{Tartışma}

Hücre içerisinde ROT konsantrasyonun artması ve oksidan-antioksidan dengesinin kontrol altında tutulamaması sonucunda oksidatif stres gelişmekte ve insanlarda kanser, diyabet, romatoid artrit ve diğer dejeneratif hastalıkların da dahil olduğu çeşitli hastalıkların gelişimine yol açabilmektedir ${ }^{20,21}$. Serbest radikaller lipidler, DNA ve proteinler gibi önemli organik moleküller ile reaksiyona girebilmekte ve bu moleküllere zarar verebilmektedirler. Dolayısıyla serbest radikalllerin organizmada meydana getirdikleri protein hasarı genellikle enzim aktivitesinin kaybına yol açarken DNA hasarı ise mutagenez ve karsinogenez ile sonuçlanmaktadır ${ }^{22}$.

Ökaryotik hücre organellerinden olan kloroplast ve mitokondriler bitki hücrelerinde iki ana enerji üretim merkezi ve reaktif oksijen türlerinin (ROT) üretim yerleri olup ayrıca 
peroksizomlar, plazma membranları, endoplazmik retikulum ve hücre duvarının çeşitli bölgeleri de ROT üretmektedirler ${ }^{23,24}$. Serbest radikaller, canlı hücrelerin organellerinde sürekli olarak üretilmektedirler ve bu moleküller çoğu zaman sinyal molekülleri olarak işlev gördükleri için serbest radikallerin üretimi genetik olarak planlanmıştır ${ }^{25,26}$. Bitki hücreleri serbest radikallerin aşırı üretimi söz konusu olduğunda serbest radikallerin olumsuz tehlikelerinin üzerinden gelebilmek için enzimatik ve enzimatik olmayan antioksidan savunma sistemlerine sahiptir ${ }^{8}$. Bitkiler tarafindan enzimatik olmayan bir süreç ile üretilen antioksidanların sentezlenmesinin ve biriktirilmesinde iki ana nedeninin olduğu düşünülmektedir. Bunlardan birincisi bitkilerin genetik yapısıdır ki bu durum bitkilerin normal fizyolojik işlevlerini yerine getirebilmeleri ve kendilerini mikrobiyal bitki patojenlerinden ve ayrıca otçul hayvanlardan korumak için çeşitli fitokimyasalları sentezleme kabiliyetlerinin olmasıdır. Indirgeyici fitokimyasalların sentezinin diğer sebebi ise bitkilerin çevresel stres koşullarına doğal olarak tepki verme eğilimlerinin olmasıdır ${ }^{27}$.

İnsanlar tarafından diyetle alınan bitkiler doğal antioksidan kaynakları olup tıbbi açıdan öneme sahiptirler ve bu özellikleri kendinde taşıyan bitkiler tüm bitkilerin üçte ikisini oluşturmaktadır ${ }^{28}$. İyi birer ekzojen antioksidan kaynağı olarak bitkiler vücudun endojen antioksidan savunmasını artırarak oksidatif stresin istenmeyen etkilerini azaltan faktörler olarak değerlendirilmektedir ${ }^{29}$.

Farklı ekstraksiyon metodları kullanılarak hazırlanan ekstraktların biyolojik aktivitelerinde de farklılıkların bulunduğu yapılan çalışmalar ile bildirilmiştir. UAE, doğal antioksidanların çıkarılmasında daha etkili ve çevre dostu olan bir yöntemdir3o. Kullanılan bu yöntemde akustik enerji gıdanın tümüne çok kısa bir zaman diliminde hızlı bir şekilde yayılarak ortamda kütle transferinin hızlı bir şekilde olmasını sağlar. Dolayısıyla gıdaların içeriğinde herhangi bir kayıp olmamakla birlikte yüksek verim ve enerji tasarrufu da sağlanmış olur ${ }^{31-34}$.

Bu çalışmada AAT Bioquest programı kullanılarak35 kuşburnu meyvesinin hem meyve kabuğu hem de çekirdek kısmı için IC50 değerleri sırasıyla 0,69 $\pm 0,005$ mg mL-1 ve 0,39 $\pm 0,0007 \mathrm{mg} \mathrm{mL}^{-1}$ olarak hesaplandı. Literatürde Serteser ve arkadaşları 2008 yılında yapmış oldukları çalışmada kuşburnu meyvesine ait DPPH radikal süpürme aktivitesine ait $\mathrm{IC}_{50}$ değerini $0.950 \mathrm{mg} \mathrm{mL}^{-1}$ olarak belirlemişlerdir ${ }^{15}$. Orhan ve arkadaşları 2009 yılında yapmış oldukları çalışmada kuşburnu meyvesine ait DPPH 
radikal süpürme aktivitesini $2 \mathrm{mg} \mathrm{mL}^{-1}$ konsantrasyonda \%79,5 olarak belirlemişlerdir ${ }^{36}$. Fattahi ve arkadaşları ise 2012 yılında yapmış oldukları çalışmada kuşburnu meyvesine ait DPPH radikal süpürme aktivitesini $\% 87,78$ olarak belirlemişlerdir ${ }^{37}$. Kumarasamy ve arkadaşları 2003 yılında yapmış oldukları çalışmada kuşburnu meyvesinin çekirdeğine ait $\mathrm{DPPH}$ radikal süpürme aktivitesine ait $\mathrm{IC}_{50}$ değerini $1,29 \mathrm{mg} \mathrm{mL}^{-1}$ olarak belirlemişlerdir38 ${ }^{8}$. Jemaa ve arkadaşları ise 2017 yılında yapmış oldukları çalışmada kuşburnu meyvesine ait $\mathrm{DPPH}$ radikal süpürme aktivitesine ait $\mathrm{IC}_{50}$ değerini o,668 $\pm 0,0017 \mathrm{mg} \mathrm{mL}^{-1}$ olarak39.

Literatürde yapılan çalışmalar ile gerçekleştirilen bu çalışma karşılaştırıldığında elde edilen sonuçlar uyumlu olup bazı çalışmalara göre hem kuşburnu meyvesi için hem de çekirdeği için daha düşük konsantrasyonlarda daha iyi DPPH radikal yakalama aktivitesi belirlenmiştir. Aynı şartlarda gerçekleştirilen Sokslet ekstraksiyonu gibi klasik yöntemler ile kıyaslandığında zamandan edilen tasarruf ile beraber kullanılan çözücü miktarının son derece azaldığı dikkat çekmektedir40.

\section{Sonuç}

$\mathrm{Bu}$ çalışmada Gümüşhane ili sınırları içerisinde doğal olarak yetişen kuşburnu meyvesinin kabuk ve çekirdek kısımlarının ultrasonik destekli etanol ekstraksiyonu ile elde edilen ekstraktların antioksidan aktivitesi araştırılmıştır. Elde edilen verilere bakıldığında 2-10 dakika zaman aralıklarında $5 \mathrm{~mL}$ etanol kullanılarak yüksek radikal yakalama aktivitesine sahip ekstraktlar elde edildiği görülmüştür. Sonuçlar zaman ve kullanılan çözücü miktarı açısından avantajlar sağlamaktadır.

\section{KAYNAKLAR}

1. Halliwell B. Free Radicals and Other Reactive Species in Disease. In: Encyclopedia of Life Sciences, UK ed. London: Wiley, John \& Sons; 2001;1-7.

2. Dupre-Crochet S, Erard M, Nübe O. ROS production in phagocytes: why, when, and where? J. Leukoc. Biol. 2013;94:657-670.

3. Zhang J, Wang X, Vikash V, et al. ROS and ROS-mediated cellular signaling. Oxid. Med. Cell Longev. 2016: e4350965.

4. Suntres ZE. Role of antioxidants in paraquat toxicity. Toxicol. 2002;180(1):65-77. 
5. Jomova K, Valko M. Advances in metal-ınduced oxidative stress and human disease. Toxicol. 2011;283(2-3):65-87.

6. Suntres ZE. Liposomal antioxidants for protection against oxidant-ınduced damage. $J$ Toxicol. 2011;(2):152474.

7. Kasote DM, Katyare SS, Hegde MV, Bae H. Significance of antioxidant potential of plants and its relevance to therapeutic applications. Int J Biol Sci. 2015;11(8):982.

8. Chanda S, Dave R. In Vitro models for antioxidant activity evaluation and some medicinal plants possessing antioxidant properties: an overview. Afr. J. Microbiol. Res. 2009;3(13):981-996.

9. Rivero RM, Ruiz JM, Garcıa PC, Lopez-Lefebre LR, Sánchez E, Romero L. Resistance to cold and heat stress: accumulation of phenolic compounds in tomato and watermelon plants. Plant Sci. 2001;160(2):315-321.

10. Winkel-Shirley B. Biosynthesis of flavonoids and effects of stress. Curr. Opin. Plant Biol. 2002;5(3):218-223.

11. Michalak A. Phenolic compounds and their antioxidant activity in plants growing under heavy metal stress. Pol J Environ Stud. 2006;15(4):523-30.

12. Cheikh-Affene ZB, Haouala F, Trabelsi N, Boulaaba M, Ksouri R, Harzallah- Skhiri F. Pomological description and chemical composition of rose hips gathered on four rosa species section caninae growing wild in tunisia. J Agr Sci Tech. 2013;1:43-50.

13. Jiménez S, Jiménez-Moreno N, Luquin A, Laguna M, Rodríguez-Yoldi MJ, AncínAzpilicueta C. Chemical composition of rosehips from different rosa species: an alternative source of antioxidants for food industry. Food Addict. Contam. Part A. 2017;34:1121-1130.

14. Ercisli S. Chemical composition of fruits in some rose (Rosa spp.) species. Food Chem. 2007;104:1379-1384.

15. Serteser A, Kargioglu M, Gok V, Bagci Y, Ozcan MM, Arslan D. Determination of antioxidant effects of some plant species wild growing in Turkey. Int. $J$. Food Sci. Nutr. 2008;59(7-8):643-651. 
16. Barros L, Carvalho AM, Ferreira ICFR. Exotic fruits as a source of important phytochemicals: improving the traditional use of rosa canina fruits in portugal. Food Res Int. 2011;44:2233-2236.

17. Roman I, Stanila A, Stanila S. Bioactive compounds and antioxidant activity of rosa canina l. biotypes from spontaneous flora of transylvania. Chem. Cent. J. 2013;7:73.

18. Demir N, Yildiz O, Alpaslan M, Hayaloglu AA. Evaluation of volatiles, phenolic compounds and antioxidant activities of rose hip (Rosa L.) fruits in Turkey. $L W T$ Food Sci Technol. 2014;57:126-133.

19. Brand-Williams W, Cuvelier ME, Berset C. Use of a free radical method to evaluate antioxidant activity. Food Sci and Technol. 1995;28:25-30.

20. Lipinski B. Pathophysiology of oxidative stress in diabetes mellitus. J. Diabetes Complic. 2001;15:203-210.

21. Rochette L, Zeller M, Cottin Y, Vergely C. Diabetes, oxidative stress and therapeutic strategies. Biochim. Biophys. Acta. 2014;1840:2709-2729.

22. Dupont GP, Huecksteadt TP. Regulation of xanthine dehydrogenase and xanthine oxidase activity and gene expression in cultured rat pulmonary endothelial cells. $J$ Clin Invest. 1992;89(1):197-202.

23. Del Río LA, Sandalio LM, Corpas FJ, Palma JM, Barroso JB. Reactive oxygen species, reactive nitrogen species in peroxisomes. production, scavenging, and role in cell signaling. Plant Physiol. 2006;141:330-35.

24. Choudhury S, Panda P, Sahoo L, Panda SK. Reactive oxygen species signaling in plants under abiotic stress. Plant Signal Behav. 2013;8:e23681.

25. Mittler R. Oxidative stress, antioxidants and stress tolerance. Trends Plant Sci. 2002;7:405-10.

26. Zhao J, Davis LC, Verpoorte R. Elicitor signal transduction leading to production of plant secondary metabolites. Biotechnol Adv. 2005;23:283-333.

27. Alscher RG, Donahue JL, Cramer CL. Reactive oxygen species and antioxidants: relationships in green cells. Physiol Plant. 1997;100:224-33. 
28. Krishnaiah D, Sarbatly R, Nithyanandam R. A review of the antioxidant potential of medicinal plant species. Food Bioprod Process. 2011;89:217-33.

29. Kasote DM, Hegde MV, Katyare SS. Mitochondrial dysfunction in psychiatric and neurological diseases: cause(s), consequence(s), and implications of antioxidant therapy. Biofactors. 2013;39:392-06.

30. Xu DP, Zhou Y, Zheng J, Li S, Li AN, Li HB. Optimization of ultrasound-assisted extraction of natural antioxidants from the flower of jatropha integerrima by response surface methodology. Molecules. 2016;21(1):2-12.

31. Chemat F, Grondin I, Shum CSA, Smadja J. Deterioration of edible oils during food processing by ultrasound. 2004;11:13-15.

32. Chemat F, Grondin I, Costes P, Moutoussamy L, Shum CSA, Smadja J. Highpower ultrasound effects on lipid oxidation of refined ultrason sonochemistry sunflower oil. Ultrason Sonochem. 2004;11:281-285.

33. Jahouach-Rabai W, Trabelsi M, Van Hoed V, et al. Influence of bleaching by ultrasound on fatty acids and minor compounds of olive oil. qualitative and quantitative analysis of volatile compounds (by SPME Coupled to GC/MS). Ultrason Sonochem. 2008;15:590-597.

34. Chemat F, Huma Z, Khan MK. Applications of ultrasound in food technology: processing, preservation and extraction. Ultrason Sonochem. 2011;18:813-835.

35. AAT Bioquest Inc. Quest Graph ${ }^{\mathrm{TM}}$ IC50 Calculator, Retrieved from https://www.aatbio.com/tools/ic50-calculator, 2020.

36. Orhan N, Aslan M, Hosbas S, Deliorman OD. Antidiabetic effect and antioxidant potential of rosa canina fruits. Pharmacogn Mag. 2009;5(20):309.

37. Fattahi S, Jamei R, Hosseını SS. Antioxidant and antiradical activities of rosa canina and rosa pimpinellifolia fruits from West Azerbaijan. Iran J Plant Physiol. 2012;2(4):523-529.

38. Kumarasamy Y, Cox PJ, Jaspars M, Rashid MA, Sarker SD. Bioactive flavonoid glycosides from the seeds of Rosa canina. Pharm Biol. 2003;41(4):237-242. 
39. Jemaa HB, Jemia AB, Khlifi S, et al. Antioxidant activity and a-amylase inhibitory potential of Rosa canina L. Afr J Tradit Complement Altern Med. 2017;14(2):1-8.

40. Cong X, Bing W, Yi-Qiong P, Jian-Sheng T, Tong Z. Advances in extraction and analysis of phenolic compounds from plant materials. Chin. J. Nat. Med. 2017;15:721-731. 